\title{
Connection Analysis of Different Modes in Multimodal Transport
}

\author{
Zhi Zhao ${ }^{1, *}$, Ya Ya Lu ${ }^{1}$, Xing Hua Liu ${ }^{1}$, Ying Jiang ${ }^{1}$, and Yan Zhou Zhang ${ }^{1}$ \\ ${ }^{1}$ Shandong Jiaotong University, Ji'nan, Shandong 250300, China
}

\begin{abstract}
As the most advanced way of transport organization, container multimodal transport provides high quality and efficient systematic logistics transportation services in a wide range of freight transport activities. So it has been widely promoted worldwide. China is in a period of sustained and rapid economic development, which needs greater support from logistics, while the rationalization of multimodal transport enables the best transport area of each transportation mode to be reflected. This paper makes an analysis of the connection between united transportation of railway and highway, rail and water transport and untied transportation of highway and water.
\end{abstract}

\section{Introduction}

Container multimodal transport is a high stage in the development of transportation. It is formed and developed on the basis of the post-industrialization background of the economic development of developed countries, the complete infrastructure and the continuous improvement of the integrated transportation system. Worldwide, as an advanced mode of freight transport, container transportation represents the development of waterway transport, railway transport and road transport. To meet the needs of modern logistics industry and develop container multimodal transport is the inevitable requirement of building a socialist harmonious society and building an economical comprehensive transportation system.

\section{Development of Multimodal Transport in China}

Multimodal transport refers to the process of systematic transportation, which is carried out by two kinds of means of transportation, which are connected and transported by each other. And each mode of transportation has its own most rationalized economic transport interval, in which the reasonable collocation of various modes of transport will be carried out, that is, the rationalization of multimodal transportation. At present, China is in the period of structural overcapacity, the cooperation between industries is particularly important. January 4, 2017, China's Ministry of Transport, the National Development and Reform Commission, and other 18 departments of the joint study on the development of a package of multimodal transport policy measures on further encouraging the implementation of the work of multimodal Transport (2016) Number No. 232). China has made clear the strategic positioning of multimodal transport from the national level for the first time. Therefore, it is an important task for multimodal transport in China to exert the comparative advantages of various modes of transportation, form a reasonable division of labor and effective cohesion, and allocate resources scientifically according to market rules. ${ }^{[1]}$

In recent years, with the rapid development of China's economy, the traffic road facilities have also achieved rapid growth, in which the development of highways is very rapid. The main trunk lines of the "five vertical and seven horizontal" national highways have basically been built, and there have also been large-scale construction of railways, waterways, aviation, and port stations. The improvement of transportation infrastructure has greatly promoted the development of container multimodal transport the rapid development of multimodal transport in China is also facing great challenges.

\section{The Connection of Several Modes of Transport in Container Multimodal Transport}

\subsection{Analysis of the Rail-water Combined Transports}

The combined transportation of waterway and railway is the main body of container multimodal transport, because the distribution of China's railways and ports has its own characteristics, so that China's waterway and railway joint transport development model is concentrated on "one-port-line multi-city" and "one-port multi-area". "The" Hong Kong line multi city "mode," port "means the port" line "for the connection between the port and inland city railway transport, A development model of combined water-iron transportation by using the extension of the main railway

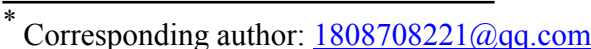


line to cover many cities. In the "one-port multi-area" model, "Hong Kong" means the main coastal ports, and "area" means the service area of the inland water free port. The development mode of "one port and multi area" is to take the coastal port as the centre, take the inland water port as the dot, and through the connection of the railway Transportation channel, form the Inland collection and transport network system with the port as the node. Among them, "waterless port" refers to a logistics centre with the functions of customs declaration, inspection, bill of lading and other port services established in inland areas, extensible range of port hinterland. Through the continuous exploration of two modes of water-iron transport development, china's water-iron-transport mode has been continuously improved.

First, Insufficient railway capacity restricts the connection between water and iron transport. The proportion of container traffic in port container throughput of Chinese railway is far lower than that of waterway in Europe and America, The lack of the capacity of railway trunk line leads to the lack of connection between port and railway, which becomes the direct reason of restricting the water and rail transport. According to incomplete statistics, the proportion of ports without railway connection in China is higher. Second, The container standardization process is slow, which restricts the connection between waterway and railway joint transportation. China is currently in the domestic container shipping transport ratio is very low, the US standard container size 53 feet, 45 feet in Europe, but China has yet to establish a standard system of inland container. First of all, the Chinese models are extremely complex, resulting in a very low degree of wishful thinking and poor compatibility between railway boxes and water containers, which makes it difficult to achieve large-scale general-purpose, thus creating a series of problems. The resulting cost of water-rail transport is much higher than expected and the figure below will quote the Chinese national standard for container external dimensions and rated quality standards.

Table 1. National Standard Container External Dimensions and Ratings

\begin{tabular}{|c|c|c|c|c|}
\hline $\begin{array}{c}\text { Contai } \\
\text { ner } \\
\text { type }\end{array}$ & $\begin{array}{c}\text { Height } \\
/ \mathbf{m m}\end{array}$ & $\begin{array}{c}\text { Width } \\
/ \mathbf{m m}\end{array}$ & $\begin{array}{c}\text { Length } \\
/ \mathbf{m m}\end{array}$ & $\begin{array}{c}\text { Rated } \\
\text { quality } \\
/ \mathbf{K g}\end{array}$ \\
\hline 1EEE & 2896 & 2438 & 13716 & 30480 \\
\hline 1EE & 2591 & 2438 & 13716 & 30480 \\
\hline 1AAA & 2896 & 2438 & 12192 & 30480 \\
\hline 1AA & 2591 & 2438 & 12192 & 30480 \\
\hline 1A & 2438 & 2438 & 12192 & 30480 \\
\hline 1AX & $<2438$ & 2438 & 12192 & 30480 \\
\hline 1BBB & 2896 & 2438 & 9125 & 30480 \\
\hline 1BB & 2591 & 2438 & 9125 & 30480 \\
\hline 1B & 2438 & 2438 & 9125 & 30480 \\
\hline 1BX & $<2438$ & 2438 & 9125 & 30480 \\
\hline 1CC & 2591 & 2438 & 6058 & 30480 \\
\hline 1C & 2438 & 2438 & 6058 & 30480 \\
\hline 1CX & $<2438$ & 2438 & 6058 & 30480 \\
\hline 1D & 2438 & 2438 & 2991 & 10160 \\
\hline 1DX & $<2438$ & 2438 & 2991 & 10160 \\
\hline
\end{tabular}

Third, The port infrastructure construction is insufficient, which restricts the connection of water and iron transport. First, China's large part of the port transport equipment, the lack of technical backwardness, resulting in a large number of human consumption. Secondly, the unreasonable construction of the station restricts the connection efficiency between the port and the railway. ${ }^{[2]}$

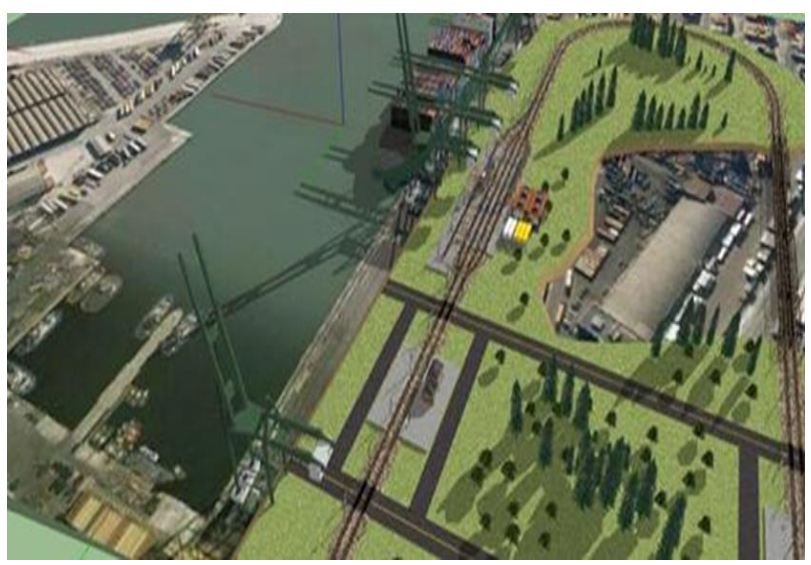

Fig.1. Combined Waterway and Rail Transport

\subsection{Analysis of Highway and Railway Combined Transport Convergence Problem}

As one of the transport modes of multimodal transport, it is an important content of China's development of integrated transportation strategy and modern logistics service model. It plays an import role in the global transportation market competition in the 21 st century. It also combines the advantages of two modes of transportation, highway and railway. Though the integration of resources, the traditional and single two modes of transportation are organically linked together to provide economical, reasonable, rapid, safe and convenient transportation services for customers. This mode of transportation service not only reduces the cost of transportation, but also improves the efficiency of transportation. It can also save energy, reduce traffic congestion and environmental pollution. In recent years, it has attracted much shortage and urban traffic congestion. At the same time, along with the rapid development of economy, the improvement of technology, information technology and advanced automation transportation equipment is widely used in the transportation industry, also has laid the foundation for the sustainable development of rail transport.

At present, the two modes transportation of China' $s$ roads and railways seem to be seamlessly connected. but since China's road transport and railway transport are managed by the Ministry of Communications and Transport and the Ministry of Railways. There are differences in the formulation of transport policies and the entry of industry, resulting in poor coordination in planning and management, and the separation of road transport and rail transport. Multitudinous transport has a variety of modes of transportation, complicated transportation routes and the full tracking of containers is 
also of vital importance. In order to ensure the security of the multimodal transport service, the whole transportation process can be monitored visually. However, the current Chinese road and rail transport does not realize the full tracking of the container.

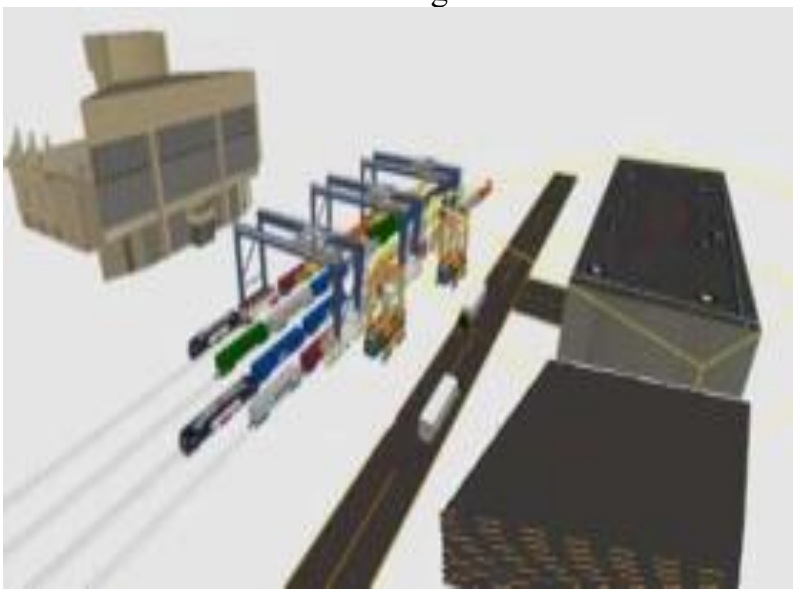

Fig.2. Combined Road and Rail Transport

\subsection{Road and Waterway Combined Transport Convergence Problem Analysis}

Public water transport is mainly by waterway transport, and road transport is a form of multimodal transport. It has the characteristics of low carbon, environment protection and sustainable development. It is a promising form of transportation organization in modern logistics industry. The adoption of combined mode of transport by road and waterway will make transport a whole, make the highway transportation and water transportation give full play to the advantages, make up the disadvantages can reduce the transportation cost while improve the efficiency of transportation, better meet the needs of customers realize the door to door service to solve the last mile distribution problem. Analysis of the connection between Public and Water Transport

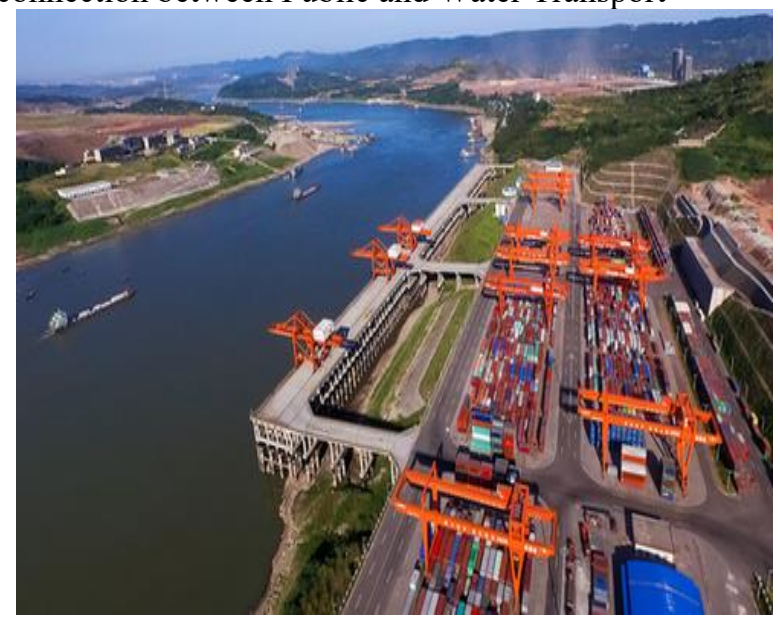

Fig.3. Combined Road and Waterway Transport

As a form of multimodal transport, there are mainly two modes of connection between public and water intermodal transport. One is to use port infrastructure in transit ports to complete transport mode changes. The other is to use the automatic force of the truck to cycle and roll so as to complete the mode of transportation change. As most of the road and waterway transport are operated independently, customs clearance and other inspection procedures are often cumbersome in the bridging process, and the lack of links between the various departments leads to a lack of coordination in planning and operation and a lack of full services. It is easy to cause delay and loss of goods, etc. which is not conducive to the low cost and efficient transportation of goods.

Because the adaptability of road transportation to freight volume, the truck's load tonnage is different, so that the container specifications used in road transportation are different, which make it more difficult to connect with waterway transportation.

\section{Recommendations and Measures}

\subsection{Advancing the Process of Container Standardization}

China's container multimodal transport is in the development stage. The unified standard has not yet been formed in the process of road, railway and water transportation. So it is impossible to realize the generalization of transport vehicles, which seriously restricts the depth of the development of multimodal transport. There is a need to further raise awareness of the standardization of container multimodal transport, to coordinate the views of all parties, and to develop and improve as soon as possible the standards for carrying units, including dimensions and tolerances, performance requirements and experimental selection standards, Marking standards and quality acceptance standards etc. That provides support for the improvement of multimodal transport to realize perfect interlinking between the links.

\subsection{Promoting Institution-building for Multimodal Transport}

Create a consistent policy environment and industry rules, concluding standardize market access, service standards and other management systems. For less open modes of transport, such as railway transport and air transport, the characteristics of public transport should be noted. In order to safeguard fairness and public interest, shippers contain freight forwarders, should be treated equally in terms of shipping qualifications, freight tariff policies and contract terms. Special inspection and demonstration should be conducted. According to the industry characteristics of multimodal transport, the scope of deductible input tax should be set up, and the chain of value-added tax deduction should be perfected. The appropriate tax rate should be set, and the system of value-added tax in transportation industry should be perfected so as to achieve structural reduction of burden. Under the guarantee of the system, the multimodal transport in China can develop towards the goal. $^{[3]}$ 


\subsection{Urgent Needs for the Construction of Information Platforms}

Information system is the blood of the development of multimodal transport. At present, China has a large number of enterprise groups, but most of the enterprise information systems have not been docked. And the enterprise information system and the national information platform have not realized the docking. In order to standardize the information of multimodal transport, we should first establish the enterprise multimodal transport information system, and implement the standards such as data interface, data exchange and so on. It is of great significance to realize the docking of information system between different transportation modes and different transportation enterprises, to promote the docking between enterprise information system and national multimodal transport information platform, and to realize the timely sharing of information.

\subsection{Establishment of Policies and Regulations to Facilitate Customs Clearance}

The Government should provide legal support for the development of multimodal transport and the convergence of various modes of transport. Aim at shortening the time for customs clearance, improving the efficiency of customs clearance, reducing transaction costs and promoting international cooperation. To promote the "one-stop operation" of international container transport, to carry out a new customs clearance mode such as "joint inspection, one release", and to carry out joint inspection and inspection of goods for the means of transport which are required to be inspected or inspected by the relevant management departments at ports. Internal Coordinate the working relationship between the railway department of the international port station and the department of "one customs; inspection and quarantine" (customs, border inspection, inspection and quarantine) departments, do parallel operations and coordinate their actions; external, coordinate well overseas To facilitate efficient transit, in particular to achieve substantial progress in the harmonization of rail waybills..$^{[4]}$

\section{Conclusion}

At present, multimodal transport is more important and urgent than ever for the development of China's logistics industry. From the point of view of China's domestic factors, the transport infrastructure should be increasingly improved, and the comprehensive transportation network should be continuously enriched and perfected. The problem of insufficient capacity in a single mode of transport has ceased to exist. The initial convergence of container transport between roads, waterways and railways has been realized, and the ability to dock trailers between roads and railways has been gradually enhanced. In the administrative system, it is hoped that in the near future, the standardization of container construction will be promoted and the information level will be levelled. The construction of Taiwan, the construction of government laws and regulations, and the perfection of multimodal transport system witnessed the rise of multimodal transport in China.

\section{References}

1. Zhao Ying, Zhou Chai Yun. Research on the current situation and Development of Multimodal Transport Standardization in China [J]. Research on quality and Technology Supervision, 2017(5).

2. Yan Xiang Bin. Deng Jun. Study on the future development strategy of water-rail combined transport $[\mathrm{J}]$. Studies on the Theory of Urban Construction (Electronic version), 2011(21).

3. Luoqiao. Study on the development countermeasures of public-water transport logistics [J]. Construction technology and design, 2017(23).

4. Yang Lei. Research on the development of container multimodal transport in China [J]. Railway transportation and Economy, 2016 (7). 